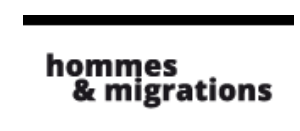

\section{Hommes \& migrations}

Revue française de référence sur les dynamiques

migratoires

Les frontières du sport

\title{
Rachid Boudjedra, Les Figuiers de Barbarie; Adlène Meddi, La Prière du Maure ; Nadia Galy, Le Cimetière de Saint-Eugène et Karin Albou, La Grande Fête
}

\section{Mustapha Harzoune}

\section{OpenEdition}

Journals

\section{Édition électronique}

URL : http://journals.openedition.org/hommesmigrations/827

DOI : 10.4000/hommesmigrations.827

ISSN : 2262-3353

Éditeur

Musée national de l'histoire de l'immigration

\section{Édition imprimée}

Date de publication : 1 janvier 2011

Pagination : 152-153

ISSN : 1142-852X

\section{Référence électronique}

Mustapha Harzoune, "Rachid Boudjedra, Les Figuiers de Barbarie ; Adlène Meddi, La Prière du Maure ; Nadia Galy, Le Cimetière de Saint-Eugène et Karin Albou, La Grande Fête», Hommes \& migrations [En ligne], 1289 | 2011, mis en ligne le 29 mai 2013, consulté le 22 septembre 2020. URL : http:// journals.openedition.org/hommesmigrations/827 ; DOI : https://doi.org/10.4000/hommesmigrations. 827

Ce document a été généré automatiquement le 22 septembre 2020.

Tous droits réservés 


\title{
Rachid Boudjedra, Les Figuiers de Barbarie; Adlène Meddi, La Prière du Maure; Nadia Galy, Le Cimetière de Saint-Eugène et Karin Albou, La Grande Fête
}

\author{
Mustapha Harzoune
}

\section{RÉFÉRENCE}

Rachid Boudjedra, Les Figuiers de Barbarie, Grasset, 2010, 266 pages, 17,50 euros Adlène Meddi, La Prière du Maure, Éditions Jigal, 2010, 171 pages, 15 euros Nadia Galy, Le Cimetière de Saint-Eugène, Albin Michel, 2010, 247 pages, 16 euros Karin Albou, La Grande Fête, Éditions Jacqueline Chambon - Actes Sud, 2010, 169 pages, 18 euros

1 L'Algérie donc, avec ces romans parus en 2010. Honneur aux aînés avec Rachid Boudjedra. Un honneur qui n'est pas seulement celui de l'âge et de la notoriété, mais qui tient surtout à la qualité de cette nouvelle œuvre. Deux amis d'enfance, Omar et le narrateur, embarquent pour un vol entre Alger et Constantine. Le premier est devenu un architecte de renommée internationale, le second est chirurgien à l'hôpital Mustapha d'Alger. Durant le vol, les deux vieux amis évoquent et se souviennent. Cette heure passée au-dessus de l'Algérie sera l'occasion pour Rachid Boudjedra de croiser l'histoire des névroses familiales et l'histoire algérienne.

2 L'écriture est dense, tantôt vindicative, tantôt poétique ou philosophique. Boudjedra sait aussi manier la serpe pour parler des "ratages" de l'existence ou des révolutions. L'histoire algérienne est dépouillée ici des vieilles lubies nationalistes. Quant à l'ancienne puissance coloniale, elle n'est pas épargnée. Mais cela n'est pas nouveau et 
quelques vérités, peut-être pas toujours bonnes à entendre de ce côté-ci de la Méditerranée, méritent bien quelques redites. Sans absoudre pour autant les nouveaux maitres d'Alger. Finis ici les longues avenues proprettes et lisses : tout est ambiguïté.

3 L'histoire alambiquée et violente de l'Algérie, l'enchevêtrement des services et des officines, les mystères du pouvoir en col blanc ou en treillis verdâtre aiguisent l'imagination des romanciers. Ce ne sont pas seulement le prétexte à quelques récits riches en rebondissements et surprises de dernières pages: il s'agit aussi de comprendre. Pour son premier roman, Adlène Meddi, rédacteur en chef d'El Watan week-end, s'en donne à cœur joie. Il embarque son lecteur dans un polar sombre où un commissaire à la retraite reprend du service pour payer une dette à un islamiste "repenti" qui, des années plus tôt, lui sauva la vie.

jo, ci-devant as de la police, tente de réactiver ses contacts pour savoir ce qu'est devenu un certain Amine, disparu nuitamment. Le hic est que tout le monde se débine, reste coi ou trop allusif. L'expérimenté Djo subodore le très mauvais plan. Le genre de celui où opèrent ces messieurs des services secrets, détenteurs du droit de vie et de mort sur tout ce qui bouge dansle pays. Et voilà justement que Madina - la fille d'un de ces "puissants pères illégitimes du pays", Hassan Lakamout, alias "Structure" - a été retrouvée assassinée dans sa voiture. Dans un parking, pas très loin de là où Amine a disparu. Il n'en fallait pas davantage pour mettre le pays au bord de la "catastrophe".

5 Adlène Meddi maîtrise son récit, évite de s'emberlificoter les crayons dans les nombreux ressorts de l'intrigue : le passé de la guerre se mêle aux horreurs du présent, les parcours individuels télescopent le fonctionnement des services, les luttes d'influences bousculent les rapports hiérarchiques, etc. Rien de nouveau sous le soleil noir du pouvoir algérien mais La Prière du maure tient en haleine et restitue un peu de cette angoisse qui doit, de temps à autre, courir dans les rues et les ruelles de la capitale algérienne, autre héros du livre.

Identité et mosaïque franco-algérienne pour Nadia Galy qui signe ici son deuxième roman après Alger, Lavoir Galant (chez le même éditeur).

Slim est orphelin de père. Il n'a pour seule famille que sa mère, la courageuse Inès.

8 Pour le fiston, papa est mort au champ d'honneur. Slim a nourri son amour filial d'une haine inextinguible contre la France. Aussi ne lui parlez pas d'aller visiter, même professionnellement, Clémentine, la jeune professeur qui vient d'aménager dans une villa d'Alger. Ou alors fissa et sans salamalecs. Mais voilà, même cela suffit à aiguiser la jalousie de Moka, le copain d'enfance qui s'est autoproclamé protecteur de Slim. Un protecteur asservi et transi d'amour. Clémentine, sans le vouloir, ni même le savoir, bousculera le bel et faux ordonnancement existentiel de Slim. L'ordre protecteur patiemment agencé par Inès va s'effondrer. Et "notre" héros, "fou d'amour patriotique et de piété filiale", "Che de son quartier", va découvrir la vérité sur son père et sur lui-même.

9 La découverte d'une filiation imprévue et d'une homosexualité nullement dilatoire chambardera l'identité, nationale et individuelle, de slim.

On retrouve ici la séduisante gouaille de Nadia Galy, mais l'allant de la phrase et l'élan romanesque, tous deux certains, achoppent parfois sur des efforts d'une construction trop visible ou peu crédible (on pense particulièrement à la rencontre entre Clémentine et Slim).

11 Karin Albou n'est pas algérienne. Comédienne et réalisatrice française, elle signe un premier roman dont l'action se situe dans un village algérien. Le récit s'ouvre sur un 
infanticide et se referme sur une naissance. Une plage algérienne sert de décor au drame, tandis qu'un hôpital parisien accueille la nouvelle vie. Entre ces deux moments se noue l'histoire d'un adultère. Celui qui unira une gamine de quinze ans environ à un homme mûr. Hassiba, bercée d'illusions romanesques, s'éprend de Selim, le mari de sa belle-sœur. La passion, incontrôlable, devra fleurir dans l'ombre, sur une plage déserte ou dans des toilettes, loin des regards de la famille et de la réprobation publique. Tout cela donne lieu à des scènes un brin torrides et à des descriptions d'émoi amoureux bien senties mais aussi à des démonstrations sociologiques moins opportunes. La littérature s'égare dans l'explicite, essentialise et charrie quelques lieux communs. Le moindre n'est pas celui d'un Selim "berbérichon" pur sucre, arabophobe, francophile et athée, opposé à un Ahmed - le beau-frère - dévot barbu, obtus et arabophone. Et Hassiba de s'interroger: "Pourquoi les hommes comme lui abandonnaient les femmes de ce pays?" Et pourtant c'est bien ce Selim qui engrosse, et par deux fois encore, une mineure qui ignorait tout des choses du sexe et qui se retrouvera seule face à son malheur. L'écriture, sensuelle, descriptive, aurait mérité ici ou là d'être retravaillée, histoire d'éviter quelques répétitions. 